\title{
Maps in video games - range of applications
}

\begin{abstract}
The authors discuss the role of the map in various game genres, specifically video games. Presented examples illustrate widespread map usage in various ways and forms by the authors of games, both classic and video. The article takes a closer look at the classification and development of video games within the last few decades. Presently, video games use advanced geospatial models and data resources. Users are keen on a detailed representation of the real world. Game authors use advanced visualization technologies, which often are innovative and very attractive. Joint efforts of cartographers, geo-information specialists and game producers can bring interesting effects in the future. Although games are mainly made for entertainment, they are more frequently used for other purposes. There is a growing need for data reliability as well as for some effective means of transmission cartographic content. This opens up a new area of both scientific and implementation activity for cartographers. There is no universally accessible data on the role of cartographers in game production, but apparently it is quite limited at the moment. However, a wider application of cartographic methodology would have a positive effect on the development of games and, conversely, methods and technologies applied by game makers can influence the development of cartography.
\end{abstract}

Keywords: cartography, computer simulators, visualizations in games, video games, virtual world

\section{Introduction}

Maps have accompanied some games for a long time. Les tables geographiques reduite en un jeu de cartes, the 17 th century card game made in Paris can serve as an example. It consisted of 52 cards. Each color represented a continent (clubs - America, diamonds - Asia, hearts - Europe, spades - Africa), and the cards represented selected places on the continents, e.g. Florida, New Mexico, Virginia. There was a map which could be used either as an accompaniment or as a base to the game. Content-wise, the cartographic elaborations weren't usually very complicated or very detailed. The situation changed dramatically in the era of video games. The first maps used in this type of games were as simple as the games themselves. Recent years, however, have shown that a very complex and detailed representation of real as well as fictional world has become a key element of the game. There have appeared amazing spatial models on the basis of real spatial data resources as well as models created by authors and users solely for the purposes of the game. It seems that a question has to be posed about the scope of using cartographic methods and technologies by game authors as well as the role of cartographers in the creation of games. The analysis presented in the article is aimed at defining the extent to which these two fields overlap and showing the necessity of making professional cartographers interested in the world of games.

\section{The map in traditional games}

Before the era of video games, board games gave cartographers quite big room for maneuver. Mid-fifties saw the beginnings of the still popular Risk. Its board is a stylized map of the world divided into territories (including Poland before the year 1795) (fig. 1). 


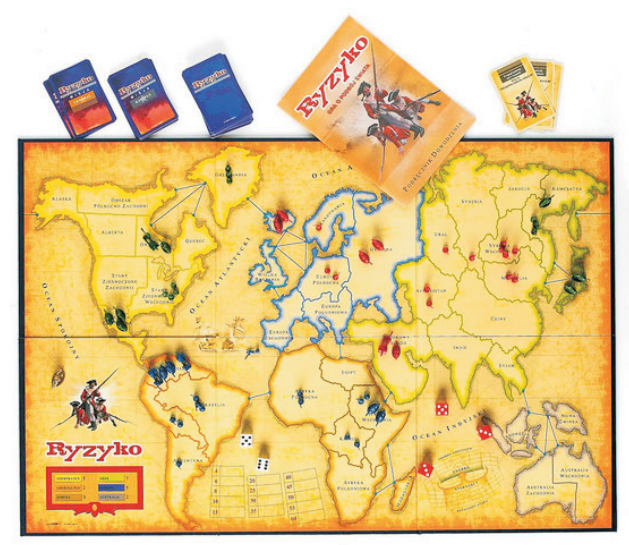

Fig. 1. Risk game board (source: [1])

God's Playground (Boże lgrzysko) is another example of a beautifully made "board map." Its title is associated with the book God's Playground: a history of Poland by Norman Davies. The board, which shows a map of the Polish-Lithuanian Commonwealth (fig. 2), can easily be called a little cartographic work of art. The game Carcassonne is an example of an interesting cartographic elaboration. Players themselves compose a map using blocks which depict elements of terrain (fig. 3).

More such examples can be found. The map in a variety of its forms is an important or key element in a great number of board games. From among the currently available ones, the following are worth mentioning: Catan, Catan: Seafarers, Ticket to Ride, 7 Ages World Map, Attack!, Axis \& Allies (fig. 4), Twilight Struggle, Paths of Glory, War of the Ring, Concordia, Tigris \& Euphrates, Pandemic, Diplomacy, Terra Mystica, A Game of Thrones and Power Grid.

\section{Video games}

Nowadays, the world of video games is strongly linked with computer technology. We play using personal computers, tablets, smartphones and video game consoles. Games are an element of contemporary mass culture. The universality of this form of entertainment makes

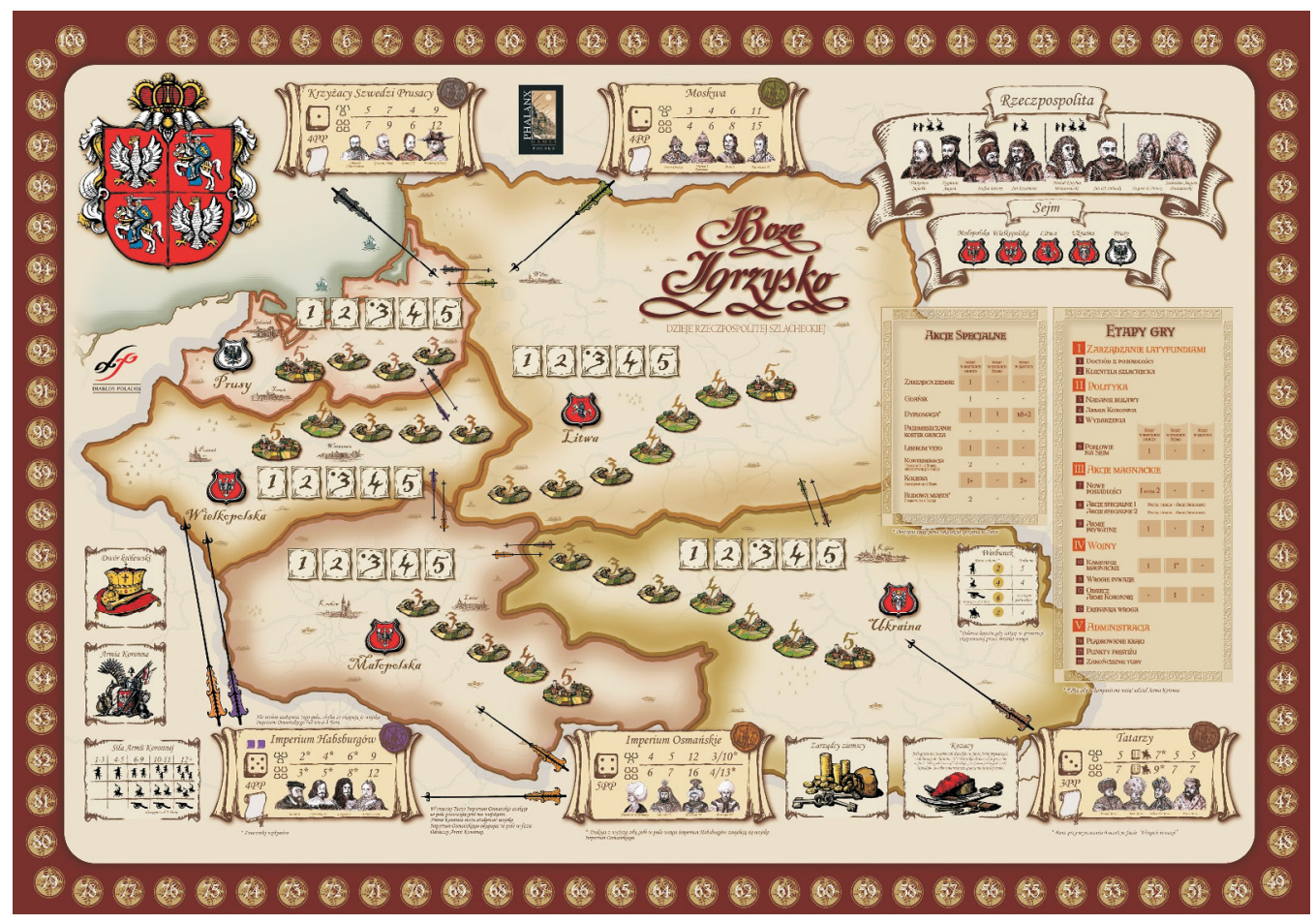

Fig. 2. God's Playground game board (source: [2]) 


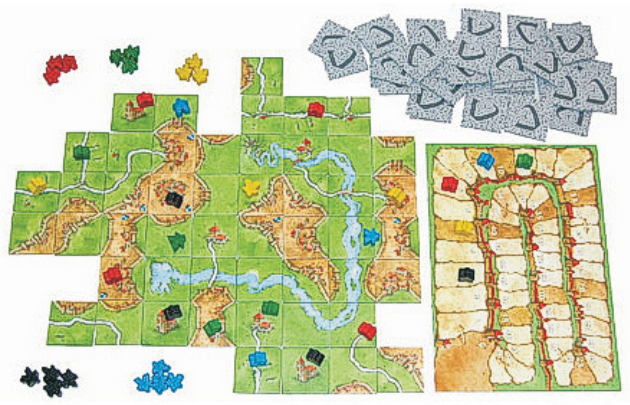

Fig. 3. Elements of the game Carcassonne (source:[3])

it easy for practically anyone to intuitively know what a video game is, but it is quite a difficult task to provide a precise definition of the idea which has functioned in common conscience for many years. Below, two definitions of a video game, differing in details, have been given: tainment. Every game has set rules and conditions for winning or improving a player's status in comparison to the starting one" [6].

There are many genres of video games. The most important ones have been presented on figure 5 .

It is worth adding that most often a game is a simulation of reality. It represents a more or less simplified model of the world. As a result of technological progress, a game can more and more faithfully reflect the real world or present an increasingly convincing image of a fantastic, made-up world. It is also necessary to emphasize such characteristics as interactivity, which makes video games more attractive than static video - information transmitted by means of traditional media, and immersion ${ }^{1}$, i.e. the possibility of plunging into the world of the game and fully engaging in play. T.W. Malone (1982) said that games which are most popular with users have defined aims, hard to predict results of action, metaphors which add imagination and

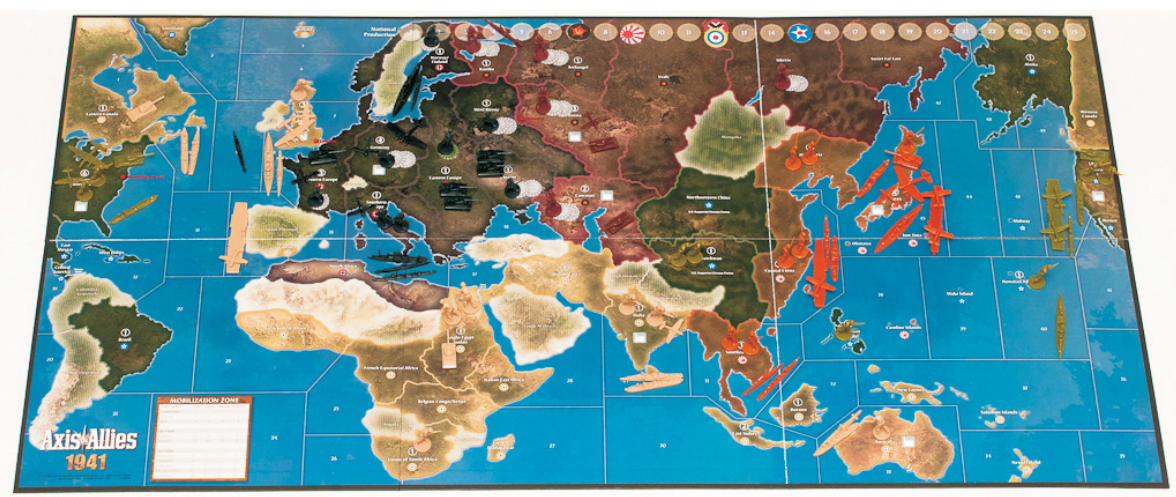

Fig. 4. Map in the game Axis \& Allies (source: [4])

$1 /$ "A video game is a computer program, recorded in any form on any digital data storage device (e.g. tape, disk, electronic circuits), performing a ludic function by allowing the manipulation of electronically generated graphic objects or text on a video screen (e.g. liquid crystal display, monitor, television) according to the rules of the game set by its authors" (S. Łukasz 1998).

$2 /$ "A video game is a computer program together with its appended data (graphics, music, sounds), whose main aim is to provide enter- build emotional engagement, and activities which spur interest through complex information and new knowledge that can be acquired.

Not more than a decade ago, games were mainly associated with entertainment for children and teenagers, but their growing importance in socio-cultural reality has changed their perception, especially since more and more adults play them. What's more, it has become apparent that games don't have to perform

\footnotetext{
${ }^{1}$ From Latin immergere - to dip, plunge, sink into.
} 
solely a ludic function. The so-called serious games, whose main goal is not entertainment, have become a new addition to the market. The player is challenged by real problems to be solved or tested, e.g. how to behave in the face of natural disasters or accidents, how to run a company or a town, learning how to operate a vehicle or a device. It is worth emphasizing that serious games do not make up a separate education, army and national defense, politics, marketing and advertising, business and science. The beneficiaries of using serious games include educational institutions, large corporations and armies. They can also function as a medium for analyzing important socio-political problems. A good example is Stop Disasters [7], the UN sponsored game, whose aim is to prepare towns and settlements in dif-

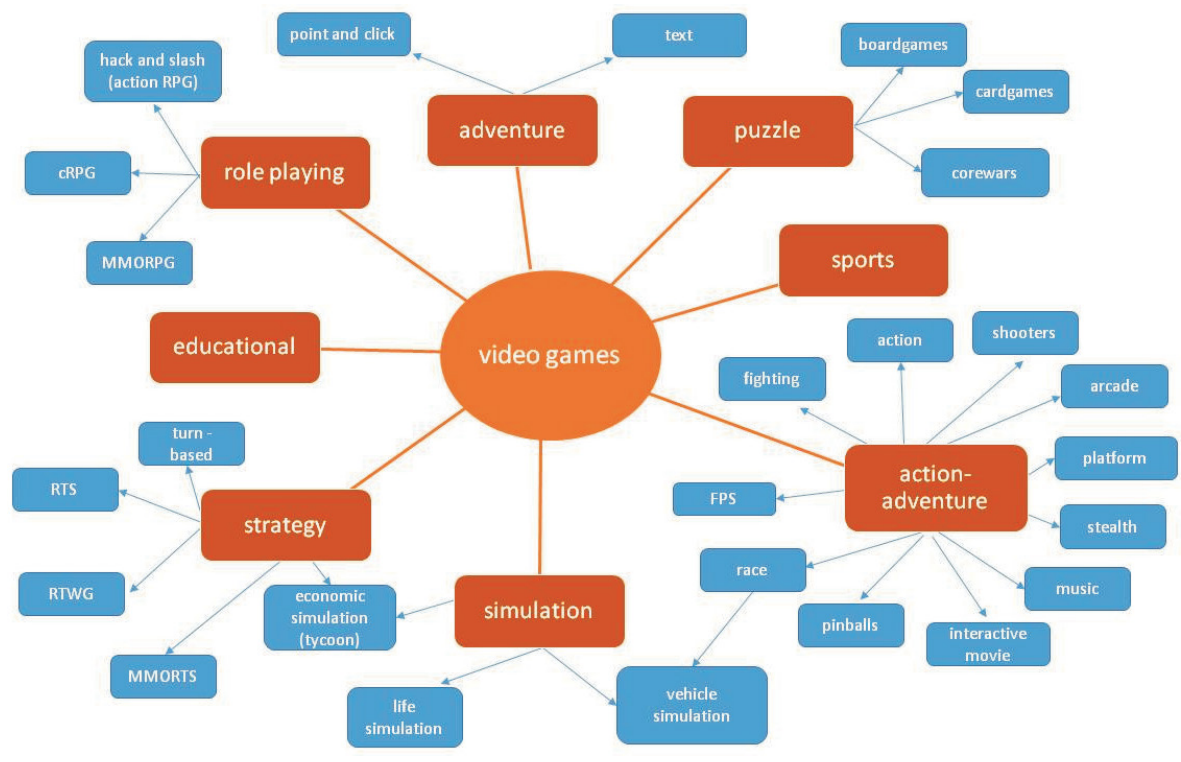

Fig. 5. Variety of video game genres - an attempt to classify genres and kinds (source: author's work)

genre, because the factor which is decisive in treating them as a separate category is the aim, not the mechanics of play. A serious game can be a game of any genre. A. Despont (2008) named six "serious" aims that these games may have:

- raising awareness,

- simulation,

- training,

- informing,

- education,

- influencing.

Creation of serious games is gaining popularity. There exist many areas in which games have become applicable, but the possibilities remain unlimited. The main areas of application are: crisis management, spatial planning, environmental protection, health protection, ferent localities in the world for natural disasters (floods, hurricanes, earthquakes, etc.).

Precise geospatial data can prove crucial in many games of this category, e.g. in training simulators for military pilots or in games about urban space planning. "Serious" games often demand "serious" data, i.e. the kind which precisely describes real locations in the world. Moreover, it is well worth noting that advanced geo-visualizations form the basis of many contemporary video games. Progress in technology has made it possible to use, without much problem, professional geospatial data resources in a way once reserved exclusively for GIS software. These facts make working on video games a challenging career environment for a 21 st century cartographer. 


\section{Connecting the world of video games and cartography}

The construction of the first electronic computers in the forties of the 20th century has started the teleinformatic revolution era. It was only natural that sooner or later computer would be also used as a game platform (the first prototype of a video game was made in 1947). The teleinformatic revolution changed the face of many domains, including cartography, for which the creation of the Canada Geographic Information System, in short CGIS, was a breakthrough. The term GIS derives from this first project. The parallel development of information technology, GIS and video games is presented on a time axis in figure 6 .
The world of video games and maps began to connect as early as in the sixties of the 20th century, when a group of computer enthusiasts in Massachusetts Institute of Technology was looking for a way to demonstrate the capabilities of the PDP-1 computer made by Digital Equipment Corporation. That was when student Steven Russell created Spacewar, in which a map of cosmic space played an important role (fig. 7).

Since those times a lot has changed. Today almost every game has some spatial aspect, which calls for the creation of a map of a part of the world, where the action takes place. The map can form the background in a multi-level platform game (e.g. Mario, Prince of Persia) as well as in a simulation game (e.g. Sims,

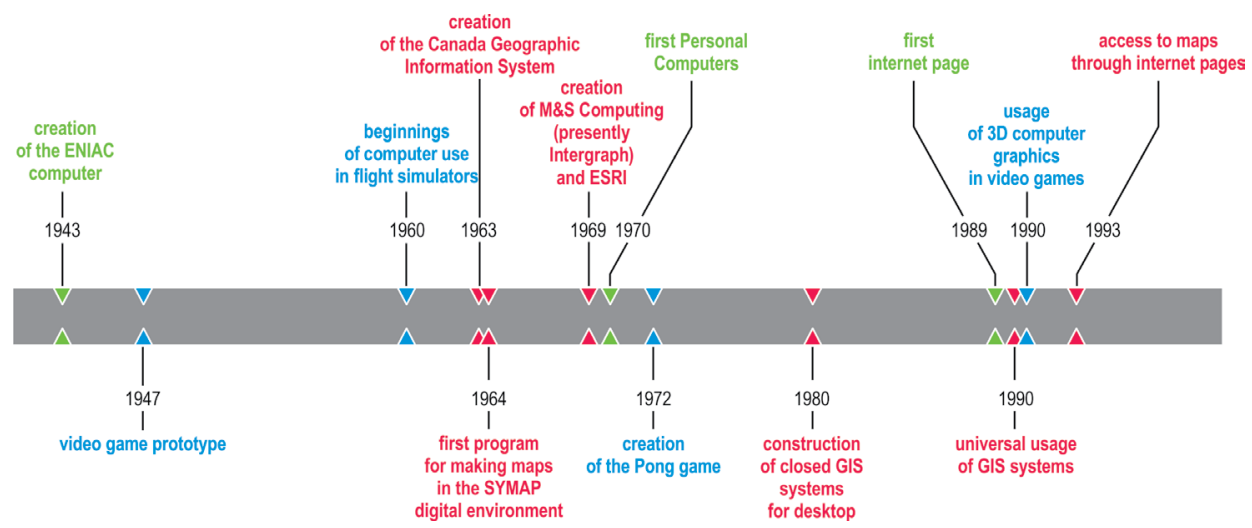

Fig. 6. Development of computers (green), GIS (brown), and computer games (blue) shown on one time axis (source: own work)

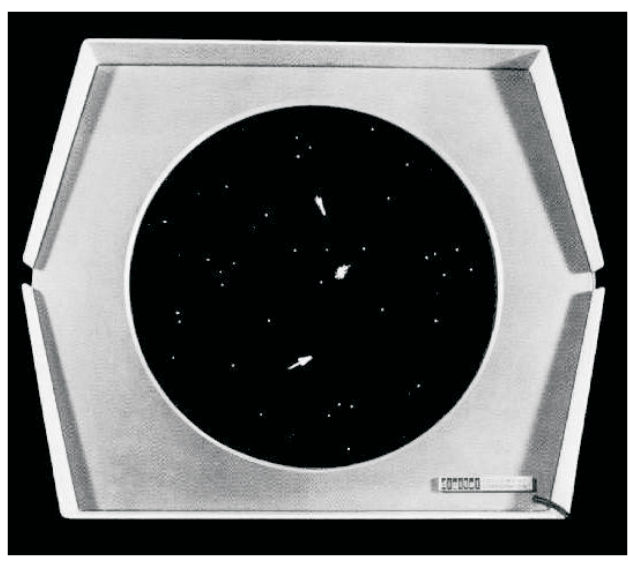

Fig. 7. Spacewar screen view (source:[5])
Farmville). The map is used to follow the results of growth of the world built by the player, or as an aid in navigating in the "open world"2 (e.g. GTA V or Skyrim). These virtual worlds become more and more complex and refined, and a well made map of the world is a mark of high quality of the game.

Presently, one of the most interesting maps is the one in the role playing game The Elder Scrolls V: Skyrim. It gives the player conside-

2 The term "open world" in video games, in a simplified way, means that the game is not limited spatially. The player may move almost completely freely in the virtual world. Moreover, the player may influence the image of the world and participate in its creation. The concept of such a game's functioning is also referred to as "sandbox." 


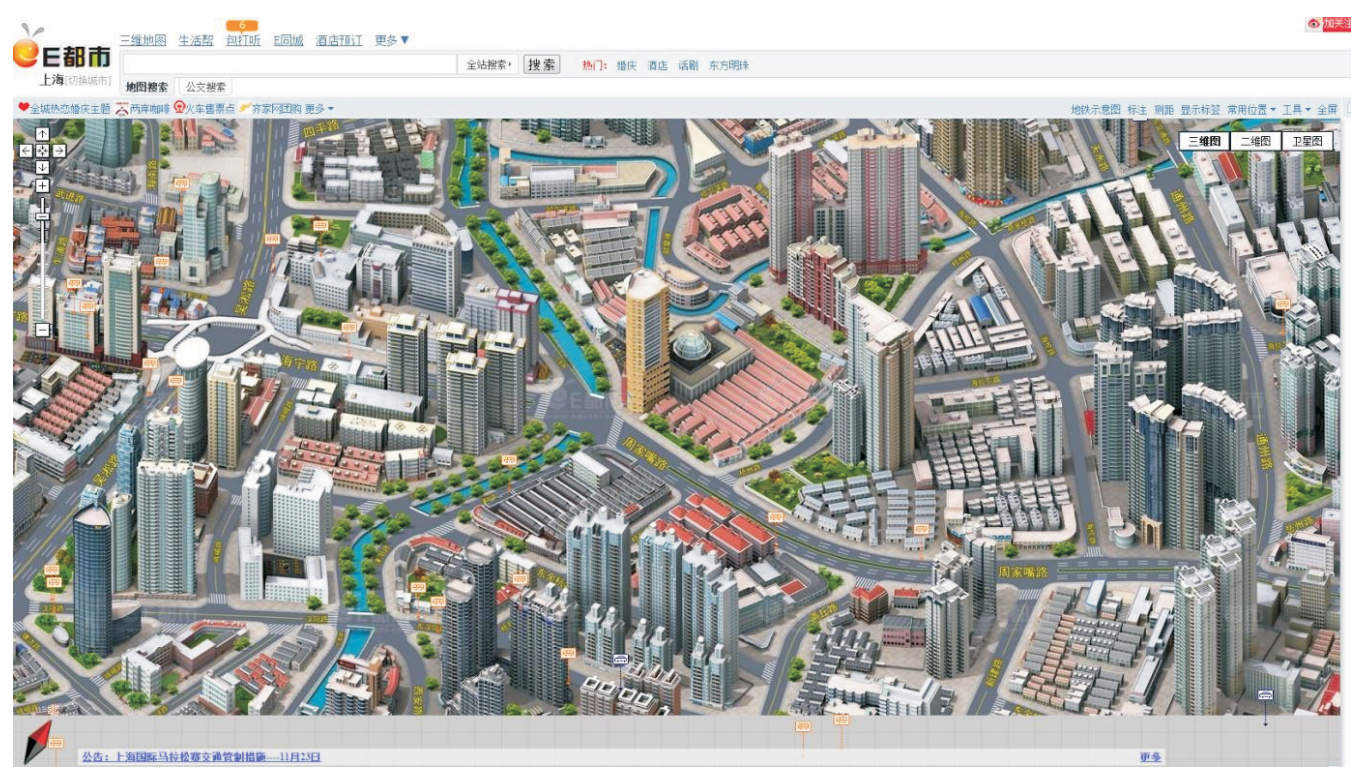

Fig. 8. Visualization of spatial data for Shanghai on Edushi.com modeled on the graphics of SimCity [10]

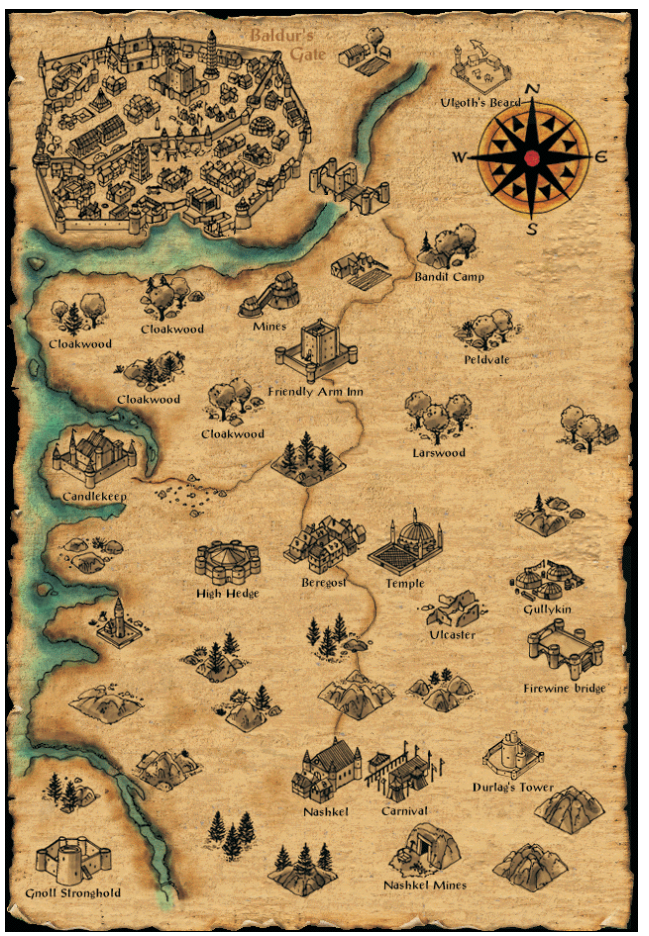

Fig. 9. Map from the cult cRPG game The Baldur's Gate (source: [11]) rable freedom of moving around in the "open world." The geographic image of the world in this game is impressive and makes playing it ineffective without a map. Creating such a vast and complex image of the world is a real challenge for cartographers.

Another noteworthy example of spatial data model usage are games in which the task of the player consists in the management of accessible means in order to build towns, restaurant networks, airports, amusement parks or even whole planets. These games are about construction, not destruction. A classic example is SimCity. It is at the same time a strategic and a simulation game which allows to implement economic strategies. In China, there is a professional spatial information system whose visualization resembles SimCity. The system is called Edushi [8] (fig. 8) and it has been made for 21 largest Chinese cities. Manhattan is pictured in a similar way on Youcity [9]. These are examples of converse interaction - the influence of games on cartography and GIS.

Role playing games are another example of the possibilities of usage of cartographic elaborations. In role playing video games the player moves an individual character or a group of characters (a team) in a virtual and most often fantastic world. Many of these games 
have their beginnings in "paper" role playing games (RPG), from which they take the concept, terminology and the so-called game mechanics. Their most important features are a rich plot, development of character skills in the course of the game and the player's considerable impact on how the plot unfolds. The precisely presented virtual world in which the player moves more or less freely is equally important. Thus classic two-dimensional maps are also an important element of this kind of games (fig. 9). A classic genre of the group is CRPG (computer role playing game), in which the creation and the development of characters, interaction with the world, a non-linear plot and abundance of tasks (the so called "quests") are the most important features. MMORPG (Massively Multiplayer Online Role Playing Games) are a broadened concept of cRPG. In these games, as in e.g. World of Warcraft, unlike in any other game genre, the authors aim at creating a virtual world in which thousands of players from all over the world may move around.

From the point of view of the development of modern cartography, First Person Shooters (FPS) are another interesting genre. Examples of such games include Quake, Doom, and
Wolfenstein. They belong to the so called action-adventure games. They have two main characteristics: observation of the world of the game is through human perspective (through someone's "eyes") and, usually but not always, they take place inside a building, which largely influences the graphics.

Especially strong ties between the world of games and cartography are visible in simulator and training games. For the majority of them, geospatial data is a key element of the game. The so called simulation scenes are managed and edited using geo-informational and cartographic methods and technologies (J.H. Haunert, C. Brenner, H. Neidhart 2005). Geo-referencing of data to a great extent facilitates integration of data from numerous sources, and thanks to the usage of real geospatial data the simulations can closely reflect events and phenomena in the real world. The most popular training games are flight simulators, both "military" and "civilian." On the market there are many universally accessible civilian aircraft simulators, which have a possibility to use geospatial data. These include Microsoft's Flight Simulator, Flight Gear (licensed as open source) and Condor Soaring Simulator, a glider flight

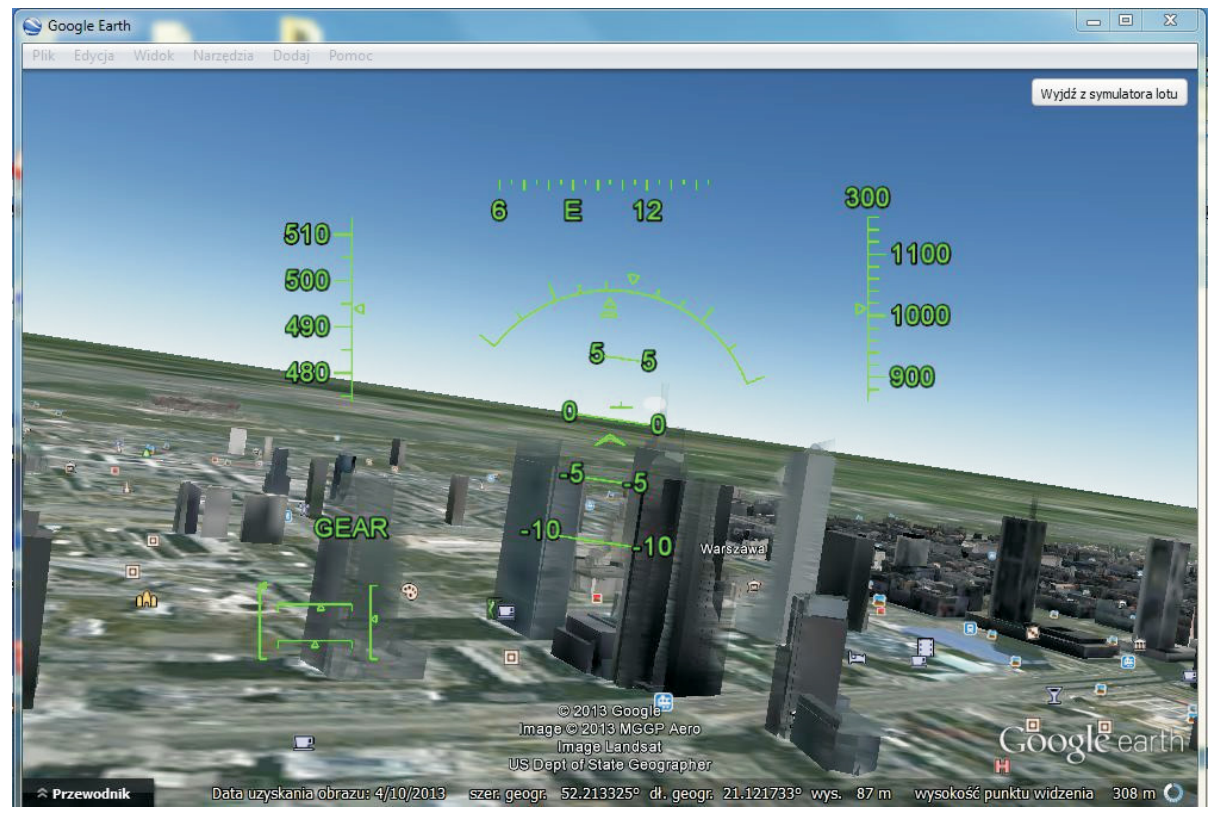

Fig. 10. Screen of Google Earth flight simulator (source: Google Earth) 


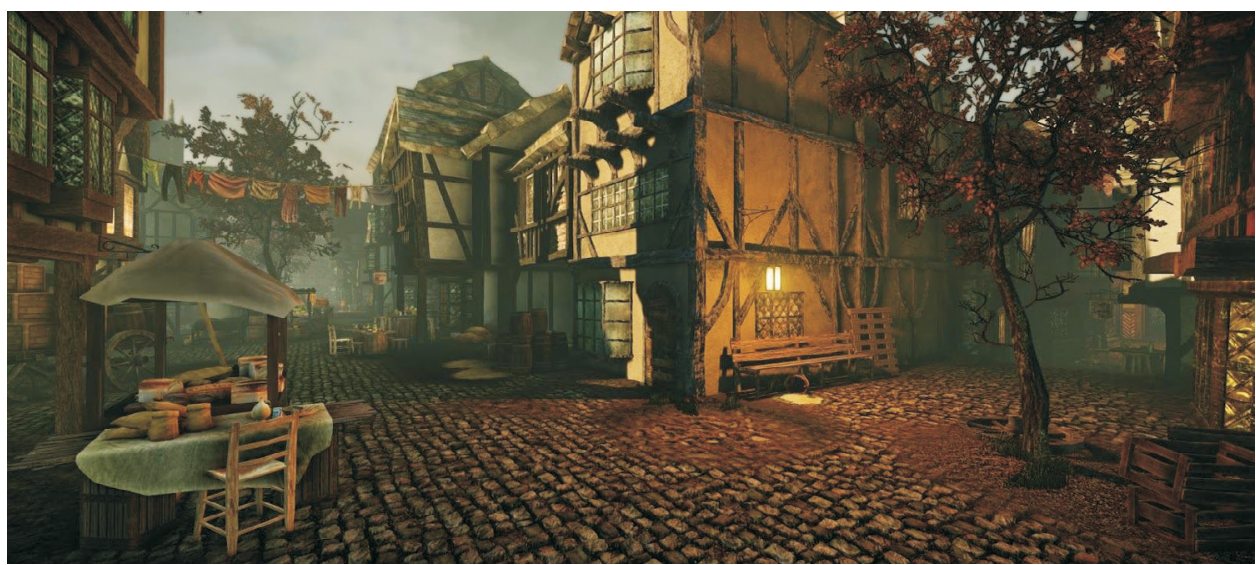

Fig. 11. Visualization of 17 th century London using the CryEngine game engine (source: [12])

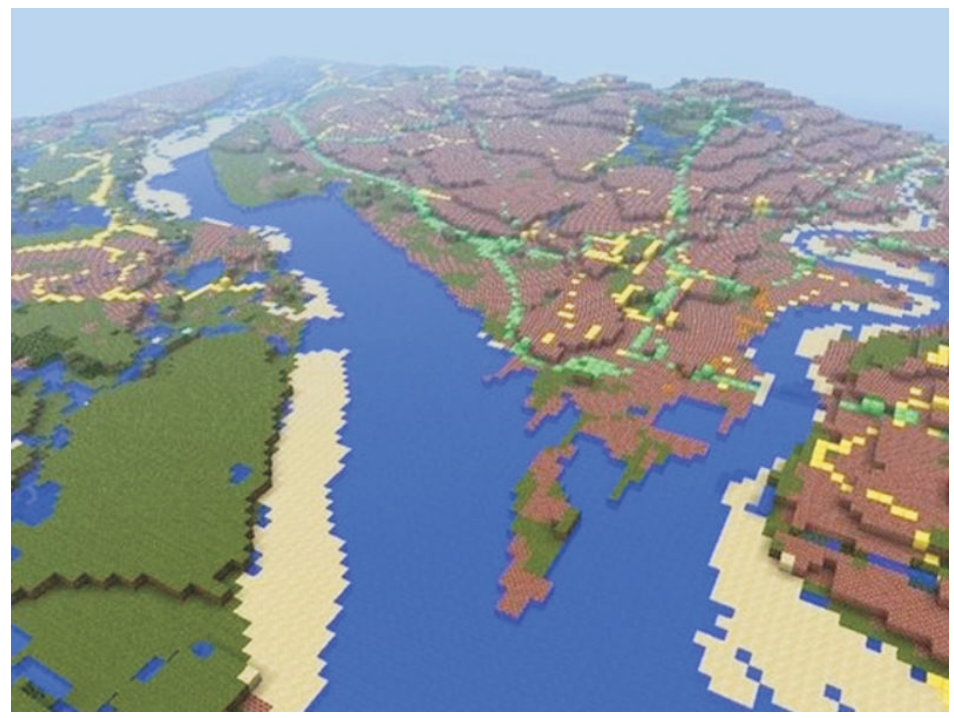

Fig. 12. Great Britain terrain model made on the basis of Ordnance Survey data (OS Open Data) and adapted to the specific needs of the game Minecraft (source: [13])

simulator. The well-known Google Earth offers flight simulation. On the basis of Google products other simulators can be created: GEFS (plane, helicopter, glider, paraglider, balloon flight simulators), Ship Simulator, Gaiagi Driver (car simulator), Monster Milk Truck (pickup truck simulator). Real models of geospatial data play a key role in them (fig. 10). It is well worth noting that training games may be also used in the event of crisis management.
In games, sometimes not only contemporary data is presented but also historical data, often a few centuries old. This opens up a lot of new opportunities not only for activities in architecture and urban planning, but also for historians and museum professionals. An interesting example is the project made by students from De Montfort University in Leicester. They used 400-year-old maps from the archives of the British Library in order to create a 17 th century 
virtual world using CryEngine - a game engine produced by Crytek. The player assumes the role of a character who travels to authentic locations and sees them the way they looked ages ago (fig. 11).

\section{Conclusion}

There is a very wide array of video games. The authors of many have used cartographic methodology and the concept of spatial information systems. To make the games function, access to complex geospatial data is indispensable. Presently, 3D models and geo-visualizations play an important role. If we accept the contemporary definition of a map as a space model (D. Gotlib 2011), then these types of imaging are directly within the range of cartographers' professional interest. There is no universally accessible data on the role of cartographers in the production of games. However, it seems that their role at the moment is quite limited. Wider usage of cartographic methodology could enrich the world of games, just like the world of games could influence the development of cartography.

The more and more frequently opened geospatial data resources can bring a new quality to computer games. On the other hand, games can popularize existing geospatial data resources or play an educational role. A good example of how public geodesy and cartography service has noticed the potential of games is the activity of

\section{References}

Despont A., 2008, Serious games et intention sérieuse: typologie (http://www.symetrix.fr/20080215serious-games-et-intention-serieuse-typologie/)

Gotlib D., 2008a, Nowe oblicza kartografii - aspekty metodyczne $i$ technologiczne. „Polski Przegląd Kartograficzny” T. 40, 2008, nr 1, pp. 21-27.

Gotlib D., 2011, Metodyka prezentacji kartograficznych w mobilnych systemach lokalizacyjnych i nawigacyjnych, „Prace Naukowe Politechniki Warszawskiej, seria Geodezja" Vol. 48, Warszawa: Oficyna Wydawnicza PW.

Haunert J.-H., Brenner C., Neidhart H., 2005, Using a GIS system for the generation of driving simulator Scenes (http://www.ikg.unihannover.de/fileadmin/ikg/staff/publications/Begutachtete_Zeitschriftenartikel_und_Buchkapitel/HaunertBrennerNeidhart_STISIM2005.pdf)

Łukasz S., 1998, Magia gier wirtualnych. Warszawa: MIKOM. the UK government agency Ordnance Survey, which provided a model of Great Britain suited to the needs of the extremely popular game Minecraft ${ }^{3}$. Both topographic and geological models were made accessible and implemented. Additionally, interestingly from the point of view of cartographic methodology, the model is generalized, built of "blocks" (cubes) (fig. 12).

If initially games were made mainly for entertainment, then today more and more frequently they also become the tools for attaining serious goals. Thus, adequate data reliability as well as effective means of cartographic presentation are required. It is possible to imagine games which e.g. draw on statistical data gathered through a census (in Poland, data from the Central Statistical Office, GUS), games based on detailed topographic models made for the needs of flood protection programs (in Poland, the ISOK project data), games based on geological data or on data from institutions in charge of national heritage (in Poland, from the National Heritage Board of Poland), etc. Cartography should take a closer look at the world of games, their genres and principles of production, and find them scientifically interesting. Broadening cartographic methodology and popularization of cartography in game producer circles is also necessary.

3 Minecraft - an exceptionally popular game (35 million copies sold globally until February 2014) which found its way to the Guinness Book of Records in several categories.
Malone T.W. (1982), Heuristics for designing enjoyable user interfaces: Lessons from computer games (http://hcs64.com/files/Malone-Heuristiques.pdf)

[1] http://bi.gazeta.pl/im/4/6001/z6001364X.jpg

[2] http://histmag.org/grafika/recenzje/bi/2.jpg

[3] http://www.acertocritico.com.br/

[4] http://www.axisandallies.org

[5] http://4.bp.blogspot.com/ NHsCIPS1G71/s1600/dec_spacewar.full.jpg

[6] http://www.gry-online.pl/S018.asp?ID=208\&STR=2

[7] http://www.stopdisastersgame.org/en/home.html

[8] http://www.edushi.com

[9] http://www.youcity.com

[10] http://sh.edushi.com/

[11] http://mikesrpgcenter.com/bgate/swordcoast.gif

[12] http://3.bp.blogspot.com/

[13] http://www.ordnancesurvey.co.uk/innovate/developers/minecraft-map-britain.html 